\title{
Coronavirus-19 Outbreak in Children: Different clinical status of a disease in children and the effect of isolation on education and social life, globally
}

\author{
Yaşar Hüseyin Onganlar ${ }^{1}$, Havva Hande Keser Şahin ${ }^{2}$, and Mustafa Şahin ${ }^{3}$ \\ ${ }^{1}$ Private Pediatrics Clinic of Onganlar \\ ${ }^{2}$ Hitit University Faculty of Medicine \\ ${ }^{3}$ Hitit University Erol Olçok Training and Research Hospital
}

October 21, 2020

\begin{abstract}
COVID-19 disease, caused by Severe Acute Respiratory Syndrome Coronavirus-2 (SARS-CoV-2), first appeared in Wuhan, China, and spread throughout the world in a short period of time (1). On 30 January 2020, WHO declared the outbreak a Public Health Emergency of International Concern (PHEIC) and than on 11 March 2020, WHO declared the Coronavirus as a pandemic. The pandemic was called as COVID-19.
\end{abstract}

\section{Hosted file}

Main Text.pdf available at https://authorea.com/users/369068/articles/487996-coronavirus-19outbreak-in-children-different-clinical-status-of-a-disease-in-children-and-the-effectof-isolation-on-education-and-social-life-globally 